\title{
Heat Shock Disrupts Long-term Memory Consolidation in Caenorhabditis elegans
}

Christine D.O. Beck ${ }^{1}$ and Catharine H. Rankin ${ }^{2,3}$

${ }^{1}$ Department of Cell Biology

Baylor College of Medicine

Houston, Texas 77030

${ }^{2}$ Department of Psychology

University of British Columbia

Vancouver, British Columbia

Canada

\section{Abstract}

Previous work has demonstrated that memory for habituation training is retained for $>24 \mathrm{hr}$ in Caenorbabditis elegans. In this study the timing of memory consolidation was investigated by introducing heat shock $\left(32^{\circ} \mathrm{C}, 45 \mathrm{~min}\right)$ either before training, long after training, or during training. It was found that memory consolidation was disrupted by heat shock during training but not before or after training. In addition, heat shock before training failed to induce thermal tolerance to the effects of heat shock during training on long-term memory formation. When brief heat shock $\left(32^{\circ} \mathrm{C}, 15 \mathrm{~min}\right)$ was presented during training at different intervals, the results suggested that a narrow critical period for memory consolidation of habituation may exist. These findings demonstrate that in $C$. elegans long-term memory for habituation is disrupted by a temporally defined agent, heat shock. Therefore, heat shock can be used as a fine-grained tool to investigate the dynamics of memory consolidation.

\section{Introduction}

Long-term memory (LTM), the retention of learning for $>24 \mathrm{hr}$, is mediated by cellular processes that are engaged during and soon after

\footnotetext{
${ }^{3}$ Corresponding author.
}

training. Work with both vertebrates and invertebrates has suggested that gene expression is necessary for the cellular processes of LTM (Flood et al. 1977; Davis and Squire 1984; Mizumori et al. 1985; Montarolo et al. 1986; Frey et al. 1988; Tully et al. 1994; Ghirardi et al. 1995). The use of invertebrate systems in which the physiology, anatomy, genetics, and development of the nervous system are accessible has been instrumental in furthering our understanding of the cellular processes underlying LTM (Montarolo et al. 1986; Tully et al. 1994; Ghirardi et al. 1995). In particular, work on the cellular processes of LTM formation in the mollusk Aplysia califormica has contributed knowledge ranging from recordings of the cellular physiology of learning to the role of specific proteins in the changes associated with LTM (for review, see Byrne et al. 1993). Long-term habituation and sensitization of the gill-withdrawal response both result in structural changes at the synapse of the sensory neurons, decreasing or increasing, respectively, the number of varicosities (presynaptic terminals), number of active zones, and the ratio of active zones to varicosities (Bailey and Chen 1983). The structural changes associated with sensitization, such as increases in the number of presynaptic active zones, the size of each zone, and the vesicle complement of each zone (Bailey and Chen 1983, 1988a,b), are blocked by transcriptional and translational inhibitors in cell culture (Schacher et al. 1991).

In the experiments reported here, the formation of LTM for habituation training is investigated in a new simple system, the nematode Caenorbabditis elegans. $C$. elegans has been successfully used as a model for the genetic control of development (Wood 1988), and the extensive background of information on the organism's biology

LEARNING \& MEMORY 2:161-177 @ 1995 by Cold Spring Harbor Laboratory Press ISSN1072-0502/95 \$5.00

$$
\begin{array}{llllllllllllllll}
\mathcal{Q} & E & A & R & N & I & N & G & E & M & O & R & Y \\
161 & & & &
\end{array}
$$


make it an excellent candidate for the investigation of cellular and molecular mechanisms of learning and memory (Rankin et al. 1990). Compared with the nervous systems of other organisms studied, that of $C$. elegans is extremely simple; all 302 neurons and their cell lineages have been identified, and the connectivity of all the neurons is known (White et al. 1986; Hall and Russell 1991). Despite this simplicity, C. elegans has a rich behavioral repertoire and is capable of a variety of forms of behavioral plasticity (Rankin et al. 1990; Bargmann 1993).

Short-term habituation has been studied in the tap withdrawal response in $C$. elegans. The tap withdrawal response is elicited when a mechanical tap is applied to the substrate on which the worm rests, causing the worm to swim backward for a short distance (Rankin et al. 1990). With repeated stimulation, the magnitude of the distance the worm swims backward, called the reversal response, decreases. Habituation of the tap withdrawal response exhibits many of the characteristics of habituation described by Groves and Thompson (1970), including dishabituation, spontaneous recovery, and sensitivity to interstimulus interval.

C. elegans is capable of LTM for habituation training for $>24 \mathrm{hr}$ (Rankin et al. 1990). Distributed training (when stimuli were given in blocks with 1-hr rest periods between blocks) appeared more effective than massed training at producing LTM for habituation training (Beck 1995; C.D.O. Beck and C.H. Rankin, in prep.), a finding that parallels results from Aplysia work on LTM formation (Carew et al. 1972; Carew and Kandel 1973). This finding led us to hypothesize that LTM formation was occurring during the rest periods of the distributed procedure. If that is so, it might be possible to disrupt LTM with treatments during the rest periods that interrupt the processes that underlie memory formation.

The agent used to disrupt LTM in the present experiments is heat shock $\left(32^{\circ} \mathrm{C}\right)$. The cellular response to heat shock (body temperature elevated at least $2-5^{\circ} \mathrm{C}$ above the optimal level) was first observed in Drosopbila (Schlesinger et al. 1982) and has since been described in every system examined, from bacteria to humans (Schlesinger et al. 1982; Lindquist 1986; Nowak 1993). The cellular response to heat shock is also evoked by other types of cellular stress such ischemia, glucose deprivation, toxins, cold, viral infections, and other damaging agents (Lindquist 1986). Heat and these other disruptive agents cause damage in the form of the denaturation and agglutination of proteins. In response, cells stop protein synthesis of all proteins except for a class called heat shock proteins (HSPs), the production of which is massively increased. These HSPs are the most widely conserved families of proteins described and appear to play a role in damage-control (Schlesinger 1982; Lindquist 1986). The presence of HSPs that are induced by an environmental agent is a marker of cellular stress in $C$. elegans and other systems (Strinham et al. 1992; Koroshetz and Bonventre 1994; Sharp and Sagar 1994).

The key characteristic of heat shock as an agent to disrupt LTM formation is that it can be delivered for short, defined periods of time, which allow us to assay the effects of a disrupting stimulus lasting as little as $15 \mathrm{~min}$. Thus, using heat shock, it is possible to examine the effects of a potentially disrupting treatment on LTM before, during, and after training but also to examine critical periods of memory formation more closely by shifting short duration treatments through them systematically.

In the first experiment reported here, the induction of an HSP gene by the heat shock treatments used in the LTM experiments was examined with a transgenic strain that has a reporter gene lac $Z$ inserted after a $b s p 16$ promoter (Stringham et al. 1992). In the LTM experiments (2-6), we examined the effects of heat shock stimuli before, during, and long after habituation training on immediate habituation, short-term retention of habituation, and long-term retention of habituation with the objective of defining a critical period for the consolidation of LTM for habituation.

\section{General Methods}

C. elegans Bristol (N2) species were maintained in 4-cm-diameter petri plates filled with 10 $\mathrm{ml}$ of nematode growth medium agar. The data from a total of 399 worms were included in the analyses of these experiments. The nematodes fed on Escherichia coli (OP50), as described in Brenner (1974). At 4 days posthatching (the peak of egg-laying), subjects were individually placed on labeled agar-filled plates at least $2 \mathrm{hr}$ training and were maintained on the same plates throughout the procedure. Worms were transferred individually from the breeding plate to the labeled plates using a bent wire pick; simultaneously, small

$$
\text { …....置"…… }
$$


amounts of bacteria sufficient to feed each subject during the study were seeded on each plate.

\section{STIMULATION AND BEHAVIORAL OBSERVATIONS}

Observations were made through a stereomicroscope with attached videorecording equipment (Wild M3Z, Wild Zeiss Canada; Panasonic Digital 5100 camera; Panasonic AG1960 VCR; NEC monitor). A time/date generator was used to superimpose the experimental time, time of day, and date on the video record (Panasonic WJ-810). The vibrational stimulus used in this work was a $6-\mathrm{Hz}$ train of six taps delivered to the side of the petri plate holding the subject. Each tap exerted $\sim 1-2$ $\mathrm{N}$ of force on the plate. The stimuli were produced by a mechanical tapper with an electromagnetic relay triggered by a Grass $\$ 88$ stimulus generator controlled by the experimenter.

The dependent measure used in this work was a measure of the magnitude of the reversal response to tap, in which the worm, either lying still or swimming forward, responds to a vibrational stimulus by initiating tail-first or backward swimming for a distance. The distance traveled during the reversal response can be quantified using stopframe video analysis and computer-driven digitizing equipment (Macintosh computer; Bit Pad Plus digitizing tablet; Macmeasure software).

\section{HABITUATION TRAINING PROCEDURE}

In experiments $2-6$, worms were trained on day 1 and tested on day 2 ( 5 days posthatching). Training consisted of 60 stimuli given in three blocks of 20 stimuli each with 1 -h rest periods between blocks of training. Within each block the stimuli were delivered at a 60 -sec interstimulus interval (ISI). In addition, in some experiments, a control group that received only a single stimulus on day 1 was included. On day 2, at least $24 \mathrm{hr}$ (24-28 hr) after the end of training on day 1 , all subjects received a test block of 20 stimuli. The performance on day 2 of the single stimulus control group was compared with the performance on day 1 and on day 2 of any group that showed a lower level of response on day 2. Long-term habituation was evident when there was a decrease in the level of response from day 1 to day 2 in a trained group and at the same time the day 2 performance of the untrained single stimulus group was comparable to the day 1 performance of the trained groups.

\section{SCORING AND STATISTICAL ANALYSES}

Reversal responses were quantified by measuring the distance traveled backward in response to the stimulus. A pause in forward swimming was scored as a reversal response of zero, as was no response to the tap stimulus. Increases in forward swimming (accelerations), $\sim 30 \%$ of the data, were considered missing data, as the magnitude of accelerations cannot be compared directly with the magnitude of reversal responses. A detailed statistical analysis of the distribution of accelerations interacting with factors such as age, day of training, expression of habituation and LTM for habituation, and heat shock presentation has been presented elsewhere (Beck 1995). The expression of long-term habituation observed in these experiments could not be accounted for by any aspect of the distribution of missing values observed; therefore, the distribution of missing values is not considered further here.

Differences in performance during habituation training were examined through analyses of the response magnitude to individual stimuli and the overall response levels during different blocks of stimuli. The response magnitude to individual stimuli were analyzed by comparing the mean magnitude of responses made to different stimuli within and between groups. The response levels to blocks of stimuli were analyzed by first calculating the mean of the magnitude of responses given by each subject during each 20 stimuli block of stimulation on day 1 and day 2 . The response levels to blocks of training were compared within and between groups. The comparisons of mean response magnitudes and block response levels were used in the analyses of both short- and long-term habituation.

Aspects of short-term habituation were examined using the data obtained during habituation on day 1 . The objective of the analyses of short-term habituation was simply to test groups for the presence or absence of short-term habituation with a number of measures; thus, each group was examined independently rather than being compared statistically with other groups. Because missing data points made repeated measures analyses impractical when considering response magnitude to individual stimuli, nonrepeated tests such as un-

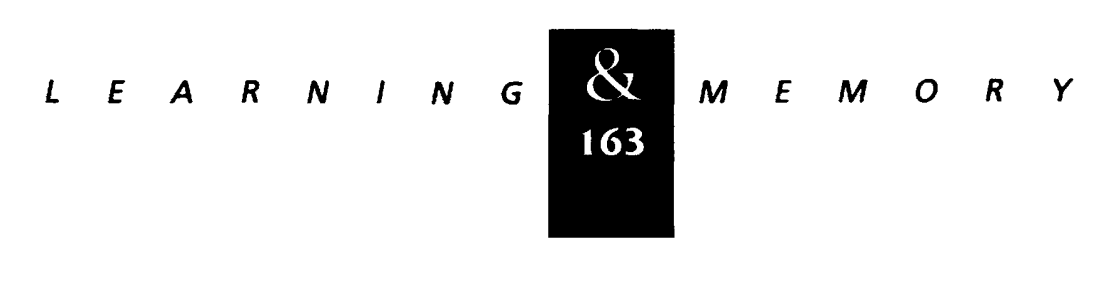


paired $t$-tests and factorial ANOVAs were used. One-tailed $t$-tests were used when a directional hypothesis was being tested (e.g., in the case of habituation, the final stimulus should be lower than the initial stimulus). The data were examined for short-term habituation using unpaired, onetailed $t$-tests to compare the response magnitudes to the first and last stimuli given on day 1 . Habituation was evident when there was a significant decrease in response magnitude during training. Habituation within each of the three training blocks was tested by comparing the response magnitude of the first and last stimuli in each block with unpaired, one-tailed $t$-tests. Recovery from habituation was considered to have occurred if an unpaired, one-tailed $t$-test showed a significant increase in response magnitude during the rest period when the response magnitude to the first stimulus of a block was compared to that of the last stimulus of the preceding block. Retention of short-term habituation during distributed training was tested in two ways. First, the response magnitude to the initial stimuli of each of the three blocks was compared with a factorial ANOVA to determine whether during distributed training the response magnitude to the initial stimulus decreased. Second, the block response levels for each of the three blocks of training on day 1 were compared with a repeated measures ANOVA to determine whether there was a significant decrease in the block response level across the three blocks.

At a 60-sec ISI long-term habituation as demonstrated in Beck (1995) is defined as a significant decrease in the level of responding from day 1 to day 2. Thus, in this experiment LTM for habituation was measured by comparing the block response level for the first block of 20 stimuli on day 1 with the block response level for the 20 stimuli on day 2; if the mean of the response level on day 2 was significantly lower than that on day 1 , the group showed long-term habituation. Once again, one-tailed $t$-tests were used because a directional hypothesis was being tested in the analysis of longterm habituation. In addition, factorial ANOVAs were employed across groups on day 1 and day 2 when appropriate.

\section{HEAT SHOCK}

The optimal temperature range for growth and development in $C$. elegans is $15-25^{\circ} \mathrm{C}$ (Wood 1988). C. elegans reacts with the production of
HSPs to temperatures over $29^{\circ} \mathrm{C}$ (Snutch and Baillie 1983). In C. elegans, the production of HSPs occurs in all cell types including neurons, demonstrating that all tissues are affected by the stress of the heat shock (Stringham et al. 1992). Heat shock proteins belonging to the HSP20, HSP70, and HSP90 families are expressed in $C$. elegans (Snutch and Baillie 1983; Russnak and Candido 1985; Heschl and Baillie 1990; Dalley and Golomb 1992). As little as $15 \mathrm{~min}$ of exposure to a temperature of $33^{\circ} \mathrm{C}$ results in the production of HSPs (Stringham et al. 1992). Yet after strong heat shock $\left(33^{\circ} \mathrm{C}\right.$, for two shifts of $2 \mathrm{hr}$ each), the worms are still viable; after heat shock they continue to reproduce and respond normally to tactile stimuli (C.D.O. Beck, unpubl.). When observed within $2 \mathrm{~min}$ after heat shock $\left(45 \mathrm{~min}\right.$ at $32^{\circ} \mathrm{C}$ ), worms are eating and moving in a coordinated fashion; they respond normally to tactile and vibrational stimuli, but their spontaneous behavior remains slightly lethargic for 3-5 min (C.D.O. Beck, unpubl.). For this reason, in the experiments presented here, an interval of $10 \mathrm{~min}$ at room temperature was allowed after heat shock before habituation training resumed.

In these experiments, heat shock $\left(32 \pm 1^{\circ} \mathrm{C}\right)$ was delivered by immersing the Parafilm-sealed petri plate, containing NGM agar and the worm, in a temperature-controlled water bath. In experiments 2-6, heat shock was given before training, during training, or after training on day 2 . When heat shock was delivered on day 1 during training, a minimum of $10 \mathrm{~min}$ was allowed after the end of heat shock exposur'? before training was resumed.

\section{Experiment 1}

\section{THE EFFECTS OF HIAT SHOCK ON bsp16 INDUCTION}

In experiment $\mathrm{L}$, the effects of the heat shock treatments on the induction of $b s p 16$, the gene of a low molecular-weight heat shock protein HSP16, in a transgenic strai $x$ by the heat shock treatments used in the LTM ex periments was tested. It is possible to insert a segrnent of DNA into an organism's genome such that w'hen a specific gene is induced, the inserted strand is also transcribed and the resulting protein is $\mathbf{s}$ inthesized. This type of transformation was perlormed to mark the transcription of a gene for a low molecular weight HSP (HSP16) in C. elegans (Stringham et al. 1992). The reporter gene in this strain is lacZ, the induction

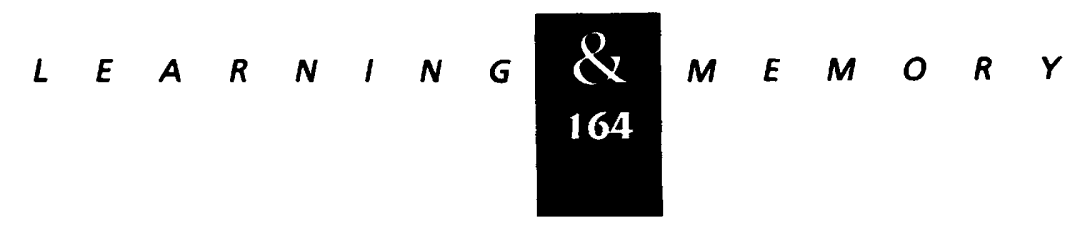


of which leads to the expression of $\beta$-galactosidase. The induction of $b s p 16$ is tightly controlled by heat shock; induction does not occur constitutively, making this gene an excellent marker for the effects of heat shock. After heat shock, the worms may be fixed and stained for $\beta$-galactosidase expression. The expression of $b s p 16$ as reported by the expression of $\beta$-galactosidase may then be examined in situ.

Although expression of $\beta$-galactosidase after induction of bsp16 cannot be used as a strict quantitative assay of HSP production, there are still relative differences in staining that relate to treatment intensity (Stringham et al. 1992). This strain was used to examine the relative effectiveness of the different heat shock treatments used in the behavioral experiments that follow.

\section{Materials and Methods}

\section{SUBJECTS}

The transgenic strain bsp16-lacZ (48.1C) was obtained from the Candido laboratory (Stringham et al. 1992). At the time of treatment, worms were 3-4 days old (at the peak of egg-laying). Twenty to 30 worms were placed on plates together. Five plates were prepared. Heat shock was delivered by immersing the plates (sealed with Parafilm) in a temperature-controlled water bath at $32^{\circ} \mathrm{C}$. Fixing and staining of the worms was done as described by Stringham et al. (1992) with a histochemical stain containing X-gal (Fire et al. 1990). The effects of four heat shock treatments on the expression of $\beta$-galactosidase were examined as well as a no-heat shock control. The four heat shock treatments were (1) single heat shock ( $45 \mathrm{~min}$ at $32^{\circ} \mathrm{C}$ ); (2) three heat shocks $\left(45 \mathrm{~min}\right.$ at $32^{\circ} \mathrm{C}$ ) given at the same intervals as used in experiments 5 and 6, starting $1 \mathrm{hr}, 20 \mathrm{~min}$ apart; (3) single heat shock ( $15 \mathrm{~min}$ at $32^{\circ} \mathrm{C}$ ); and (4) three heat shocks $\left(15 \mathrm{~min}\right.$ at $32^{\circ} \mathrm{C}$ ) given at the same intervals as the 45-min heat shocks. After the end of heat shock treatment, the worms were allowed to rest for $\mathbf{3 0}$ min to permit the $\beta$-galactosidase to develop (Stringham et al. 1992). The animals were then fixed and stained as described by Stringham et al. (1992).

\section{ANALYSIS}

The analysis was a qualitative judgment of staining intensity. Photographs of representative staining after each of the treatments are presented here. A positive heat shock control (same strain, heat shock at $33^{\circ} \mathrm{C}$, for $30 \mathrm{~min}$ ) performed by the Candido laboratory is also presented for comparison.

\section{RESULTS}

As can be seen in Figure 1, there was staining after all heat shock treatments, but none in the no-heat shock control group. Overall, it appears there was a dose-effect in staining intensity expressed between the 15 - and the 45 -min heat shock. The incomplete staining seen here (not all cells show staining) is typical of this assay and may be attributable to incomplete expression of $b s p 16$. Interestingly, it seems that staining after three heat shocks ( $45 \mathrm{~min}$ at $32^{\circ} \mathrm{C}$ ) was no more intense than the staining after a single heat shock ( $45 \mathrm{~min}$, $32^{\circ} \mathrm{C}$; see Fig. 1 ).

These results indicate clearly that the heat shock treatments used in experiments $2-6$ caused cellular stress marked by the induction of $b s p 16$, a gene for HSP16, a low molecular weight HSP. Having demonstrated that these protocols cause HSP induction, the effects of these heat shock treatments on short- and long-term retention of habituation were examined in experiments 2-6.

\section{Experiment 2}

\section{SHORT- AND LONG-TERM HABITUATION WITH PRE-EXPOSURE TO HEAT SHOCK}

In this experiment the effects of the pre-exposure to heat shock on the expression of habituation and long-term habituation are examined. The presence of the HSPs themselves may affect the later expression of short- or long-term habituation. In addition, a history of cellular stress may have consequences for learning and memory processes. To test these possibilities, heat shock was administered before training, and the habituation expressed during training and testing was compared with that of similarly trained controls that did not receive heat shock.

\section{Materials and Methods}

The first group, LTH $(n=20)$, received habituation training on day 1 and was tested on day 2 . The second group, PRE HS/LTH $(n=20)$, received

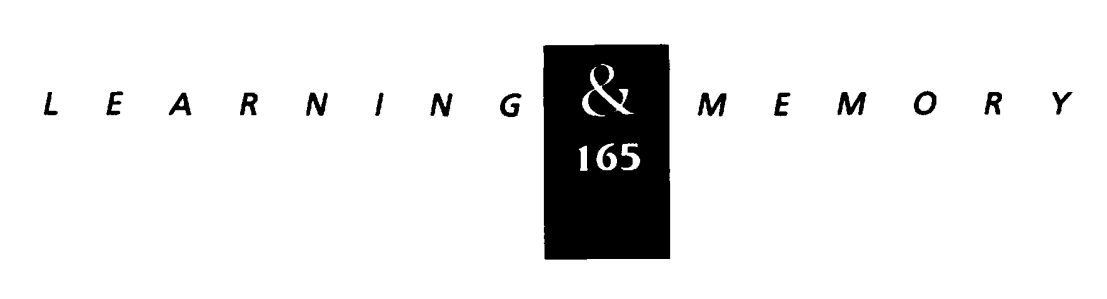


Figure 1: The expression of lacZ in transformed $C$. elegans. In this strain, lacZ has been inserted behind the promotor of hsp 16. The heat shock treatments were the ones used in the behavioral experiments (experiments 2-6). No heat shock controls; positive heat shock controls (con) (Candido laboratory); single heat shock (HS) $\left(15 \mathrm{~min}\right.$ at $\left.32^{\circ} \mathrm{C}\right)$; three heat shocks $\left(15 \mathrm{~min}\right.$ at $\left.32^{\circ} \mathrm{C}\right)$ at $1 \mathrm{hr}$ and 20 min intervals; single heat shock (45 min at $\left.32^{\circ} \mathrm{C}\right)$; three heat shocks $(45 \mathrm{~min}$ at $32^{\circ} \mathrm{C}$ ) at $1 \mathrm{hr}$ and $20 \mathrm{~min}$ intervals.
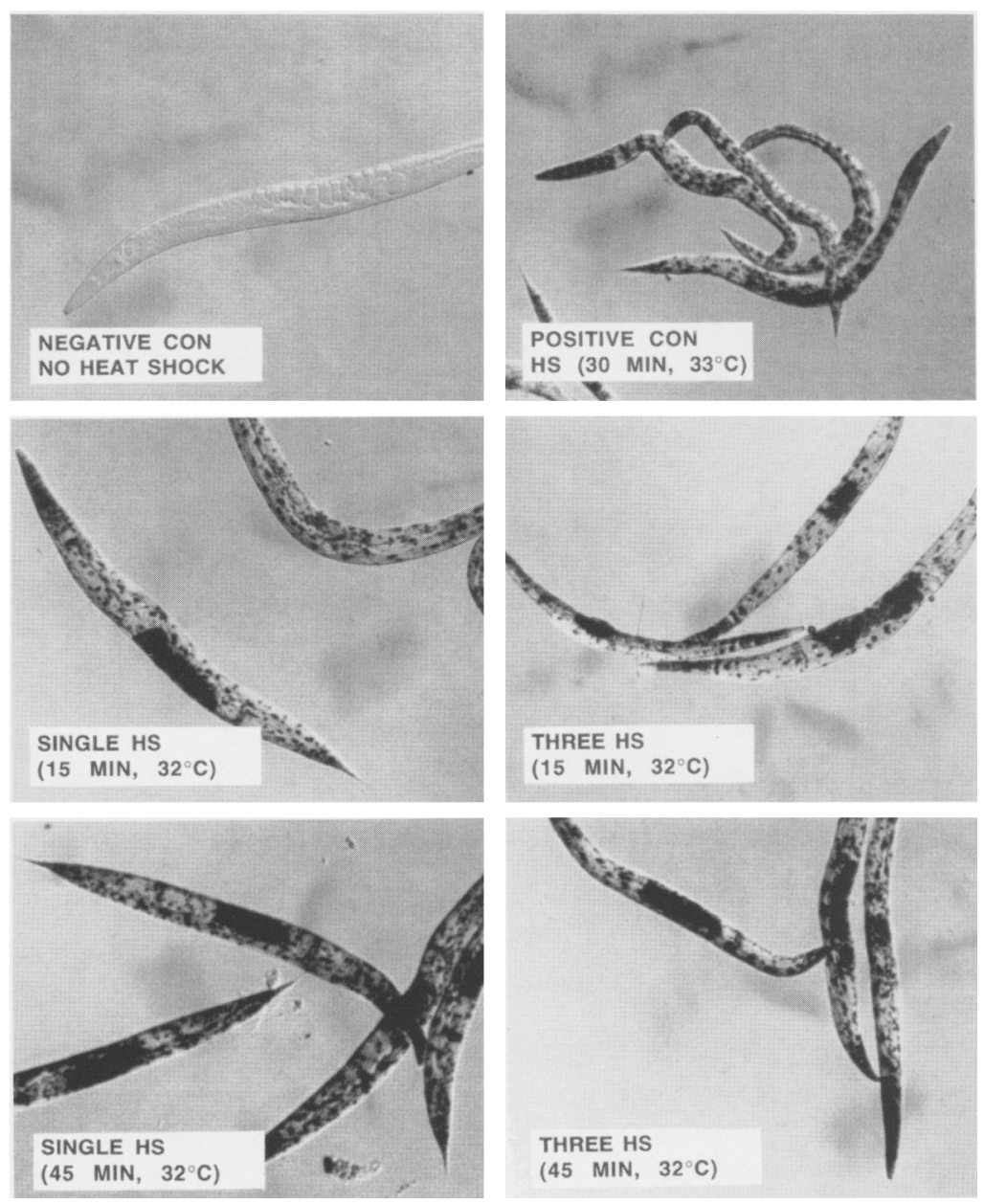

a heat shock ending $2 \mathrm{hr}$ prior to behavioral training, and then received the same training and testing as the LTH group.

\section{Results}

\section{IMMEDIATE HABITUATION}

Both the LTH (Fig. 2A) and PRE HS/LTH (Fig. 2B) groups showed significant habituation over all the training on day 1 as seen in the significant decrease of the response magnitudes from the initial stimulus to the final stimulus of training [unpaired, one-tailed $t$-tests-LTH: $t(30)=3.991$, $P<0.01$; PRE HS/LTH: $t(29)=4.783, P<0.01$ ]

Within all blocks of training on day 1 , both groups showed significant response magnitude decrement as seen in comparisons of the initial and final responses of each block. In both groups, the response magnitude decreased in each block [unpaired, one-tailed $t$-tests-LTH, block 1: $t(30)=4.68, P<0.01$; block $2: t(29)=2.511$, $P<0.01$; block 3: $t(31)=5.437, P<0.01]$. Recovery from habituation, as indicated by a significant increase in the response magnitude from the end of one block to the beginning of the next, was evident between the second and third blocks of both groups but not between the first and second blocks [unpaired, one-tailed $t$-tests-LTH, block 1 to block 2: $t(28)=1.701$, N.S.; block 2 to block 3: $t(33)=3.281, P<0.01$; PRE HS/LTH, block 1 to block 2: $t(33)=0.784$, N.S.; block 2 to block 3 : $t(28)=2.265, P<0.02]$.

\section{SHORT-TERM RETENTION OF HABITUATION}

Short-term retention of habituation would be exhibited as a significant decrease in response levels across the blocks. There was a significant decrease in the response magnitude to the initial

$$
\text { ….... 圆 }
$$




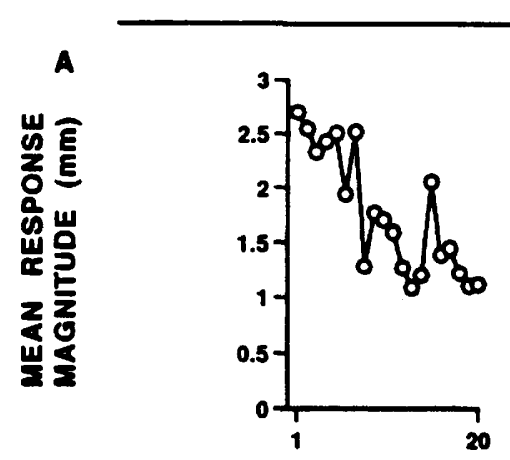

DAY 1
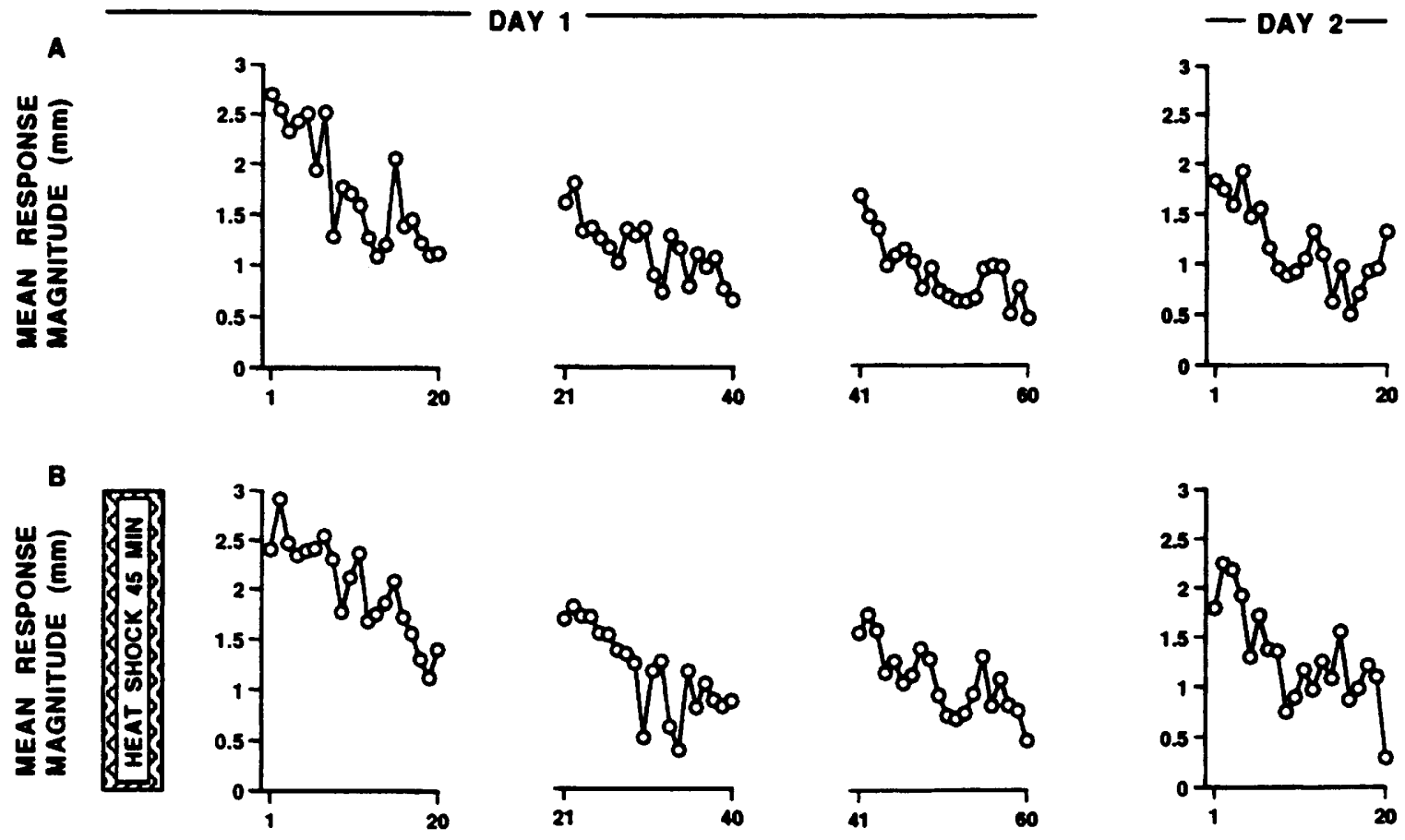

\section{STIMULI}

Figure 2: Habituation curves: distributed habituation training with pre-exposure to heat shock $\left(45 \mathrm{~min}\right.$ at $\left.32^{\circ} \mathrm{C}\right)$. The mean response magnitude $(\mathrm{mm})$ to each stimulus given during training on day 1 and testing on day $2,24 \mathrm{hr}$ after the end of training, is shown for subjects receiving distributed habituation training only [(A) LTH; $n=20 ; 60$ stimuli in three blocks of 20 stimuli at a $60-\mathrm{sec}$ ISI with 1 -hr rests between blocks)], and subjects receiving distributed habituation training $2 \mathrm{hr}$ after the end of a $45 \mathrm{~min}$ heat shock [(B) PRE HS/LTH; $n=20$ ].

stimuli of each block in both groups [factorial ANOVAs-LTH: $F(2,46)=9.281, P<0.01$; PRE HS/ LTH: $F(2,51)=6.529, P<0.01$; see Fig. 2]. Fisher's post hoc comparisons showed that in both groups, the block 1 initial stimuli response magnitudes were significantly greater than those in blocks 2 and 3 . In addition, when the block response levels of three blocks were compared within each group, both groups showed a significant decrease in response levels across the blocks [repeated measures ANOVA-LTH: $F(2,38)=31.373, P<0.01$; PRE HS/LTH: $F(2,38)=38.363, P<0.01$ ]. Fisher post hoc comparisons showed that in the LTH group, the block 2 response level was significantly lower than the block 1 response level and the block 3 response level was significantly lower than the block 2 response level. In the PRE HS/LTH group, the response levels from blocks 2 and 3 were significantly lower than the block 1 mean. Thus, there was short-term retention of habituation across blocks of training in both groups.

\section{LONG-TERM RETENTION OF HABITUATION}

Retention of habituation training should be evident as a lower level of responding on day 2 than on day 1 . To test this, the mean of the first 20 responses on day 1 were compared to the mean of the 20 responses on day 2 for each worm. In both the LTH and PRE HS/LTH groups, the response level on day 2 was significantly. lower than that on day 1 , indicating that there was significant long-term retention of habituation in both groups [see Fig. 3; paired, one-tailed $t$-tests-LTH: $t(19)=4.15, P<0.01 ;$ PRE HS/LTH: $t(19)=5.146$, $P<0.01]$.

\section{THE EFFECTS OF PRE-EXPOSURE TO HEAT SHOCK}

Although no major differences were evident between the two groups when the immediate habituation, and short- and long-term retention for

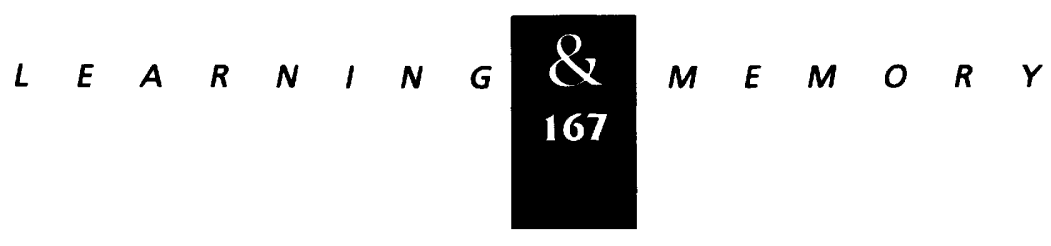




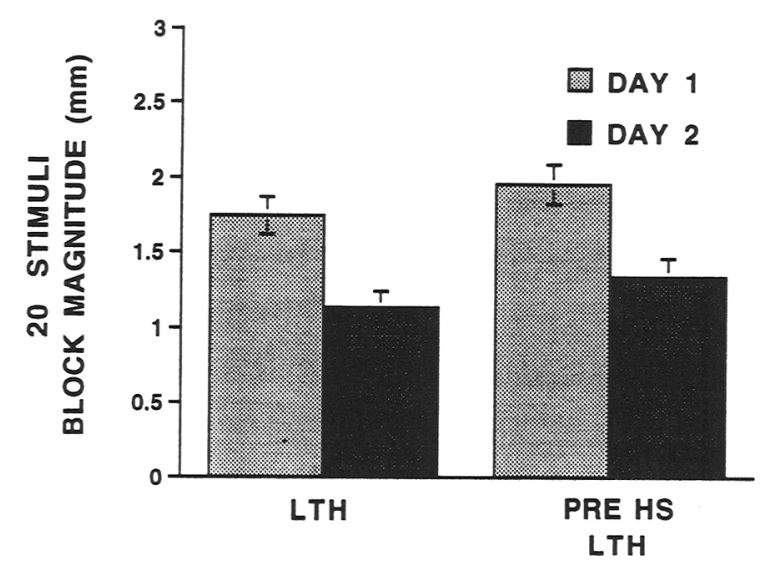

Figure 3: Habituation by block: distributed habituation training with pre-exposure to heat shock ( $45 \mathrm{~min}$ at $32^{\circ} \mathrm{C}$ ). The mean block magnitudes on day 1 and day 2 of the two groups [(LTH) distributed training only, $n=20$; (PRE HS/LTH) distributed training with pre-exposure to heat shock, $n=20$ ] are shown (error bars show \pm S.E.

habituation were examined in each, there may be differences because of the pre-exposure to heat shock that would be evident when the groups are compared directly. Heat shock may have affected the initial level of response on day 1 or the degree of long-term habituation across the days. Across groups, we can compare the response to the initial stimulus on day 1 and block response level to the first block on day 1 . As is evident in Figure 2, $A$ and $B$, there was no significant difference in the magnitude of the response to the initial stimuli on day 1 [unpaired, two-tailed $t$-tests; $t(34)=0.99$, N.S.] In addition there was no significant difference in the block 1 response levels between groups [unpaired, two-tailed $t$-test; $t(38)=1.18$, N.S.] Thus, pre-exposure to heat shock $2 \mathrm{hr}$ prior to training does not affect short-term or long-term retention of habituation.

\section{Experiment 3}

\section{SHORT- AND LONG-TERM HABITUATION WITH HEAT SHOCK DURING TRAINING}

Previous work with agents that disrupt LTM has shown that memory formation was vulnerable to disruption during and immediately after training (Frey et al. 1988; Castellucci et al. 1989). Here, the effects of heat shock delivered during each of the 1 -hr rest periods immediately after each train- ing block on the expression of habituation, and the retention of short- and long-term habituation are examined.

\section{Materials and Methods}

Two groups were run. The first group, LTHHS ( $n=18)$, received habituation training; Immediately after each of the three training blocks during the 1-hr rest periods, worms were exposed to a heat shock ( $32^{\circ} \mathrm{C}$ for $45 \mathrm{~min}$ ). A minimum of 10 min passed after the end of the heat shock and the resumption of training. The second group, HS $\operatorname{ONLY}(n=18)$, received no training on day 1 but received the heat-shock exposures at the same intervals as the LTH-HS group. Both groups were tested on day 2 with 20 stimuli.

\section{Results}

\section{IMMEDIATE HABITUATION}

As can be seen in Figure $4 \mathrm{~A}$ by comparing the response magnitudes to the initial and final stimuli of training, the LTH-HS group exhibited habituation during training. There was a significant decrease in the response magnitude [unpaired, onetailed $t$-test, first and last stimuli of day 1 training; $t(25)=4.821, P<0.01]$.

Within all blocks of training on day 1 , the LTH-HS group showed significant habituation as seen in comparisons of the initial and final responses of each block. The response magnitude decreased significantly in each block [unpaired, one-tailed $t$-tests, first and last stimuli of each block-block 1: $t(29)=2.518, P<0.01$; block 2 : $t(22)=2.762, P<0.01$; block 3: $t(22)=2.555$, $P<0.01]$. Recovery from habituation, as indicated by a significant increase in the response magnitude from the end of one block to the beginning of the next, was evident between the second and third blocks but not the first and second blocks [unpaired, one-tailed $t$-tests-block 1 to block 2: $t(28)=0.303$, nonsignificant (N.S.); block 2 to block 3: $t(20)=3.163, P<0.01]$.

\section{SHORT-TERM RETENTION OF HABITUATION}

Short-term retention of habituation would be exhibited as a significant decrease in response levels across the blocks. A significant decrease in the response magnitude to the initial stimuli was

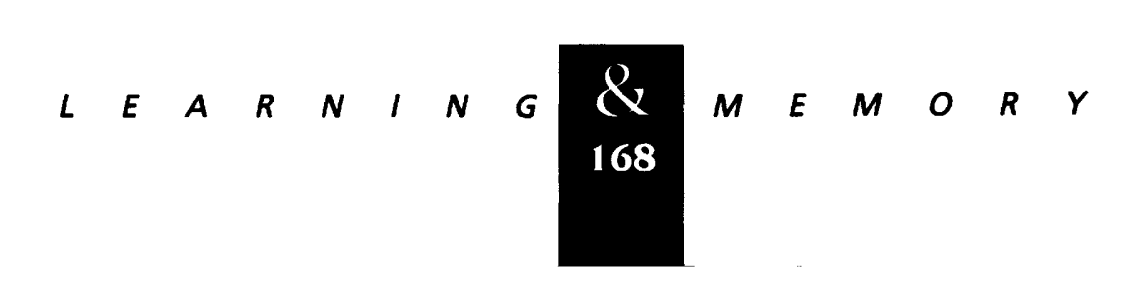




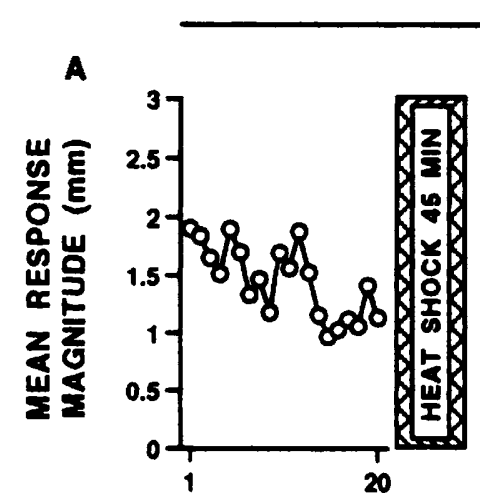

DAY 1 - DAY 2 -
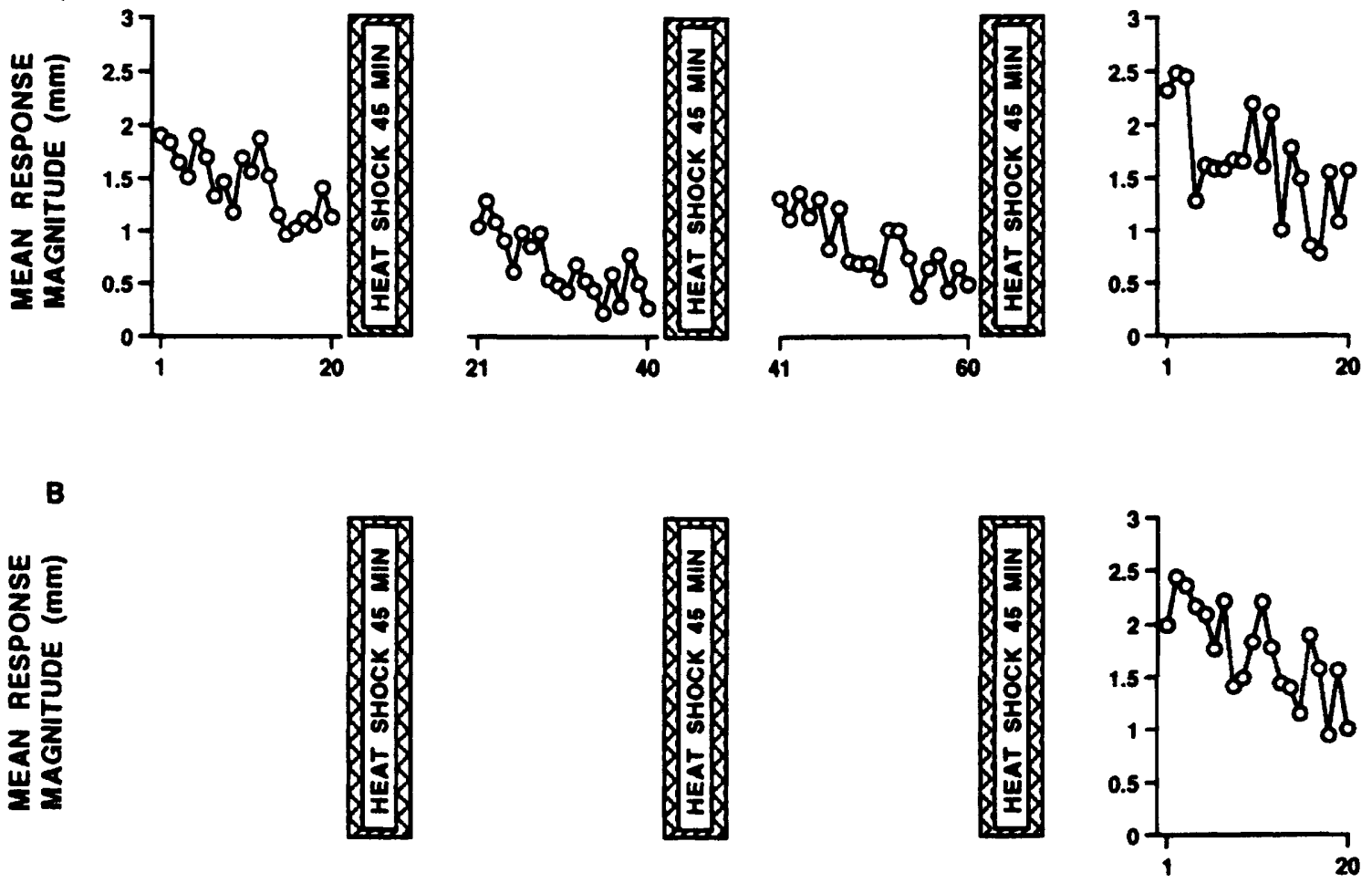

STIMULI

Figure 4: Habituation curves: distributed habituation training with heat shock $\left(45 \mathrm{~min}\right.$ at $\left.32^{\circ} \mathrm{C}\right)$ during training. The mean response magnitude $(\mathrm{mm})$ to each stimulus given during training on day 1 and testing on day $2,24 \mathrm{hr}$ after the end of training, is shown for subjects receiving distributed habituation training (60 stimuli in three blocks of 20 stimuli at a 60 -sec ISI with 1-hr rests between blocks) with heat shock (45 min at $32^{\circ} \mathrm{C}$ ) after each of the three training blocks [(A) LTH-HS; $n=18)$ ], and subjects receiving heat shock $\left(45 \mathrm{~min}\right.$ at $\left.32^{\circ} \mathrm{C}\right)$ at the same intervals as the LTH-HS subjects, but without habituation training [(B) HS ONLY; $n=18$ ].

found in the LTH-HS group [see Fig. 4A; factorial ANOVA; $F(2,41)=4.573, P<0.02$ ]. Fisher post hoc comparisons showed that there was a significant decrease in the initial response magnitude between blocks 1 and 2 but not between blocks 2 and 3 . In addition, when the block response levels of the three blocks were compared, there was a significant decrease in response levels across the blocks [repeated measures ANOVA; $F(2$, $38)=28.105, P<0.01$ ] . Fisher post hoc comparisons showed that the block response magnitudes decreased significantly from block 1 to block 2 . Thus, there appears to be short-term retention of habituation when heat shock is presented during training.

\section{LONG-TERM RETENTION OF HABITUATION}

Retention of habituation training would be evident as a lower level of response on day 2 than on day 1 . To test whether the LTH-HS group exhibited LTM for habituation training, the mean of the first 20 responses on day 1 were compared to the mean of the 20 responses on day 2. After heat shock during habituation training, the level of responding on day 2 was not significantly different from the day 1 response level [paired, two-tailed $t$-test; $t(17)=0.769$, N.S.], not less than the response level on day 1 as would be expected if there were LTM for habituation (see Fig. 5). Therefore, after heat shock during habituation training, there was no long-term retention of habituation training.

THE EFFECTS OF HEAT SHOCK DURING TRAINING ON PERFORMANCE

Whereas the expression of habituation during training and the short-term retention of habitua-

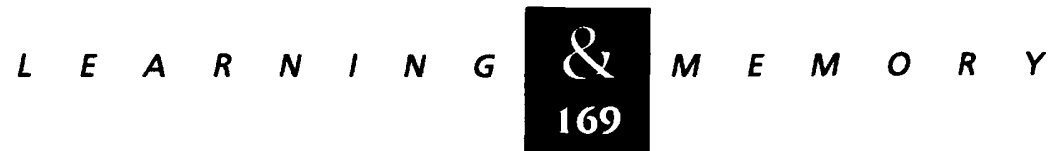


tion were not blocked by heat shock during training, long-term retention for habituation was lost. C.D.O. Beck and C.H. Rankin (in prep.) showed that without training on day 1 , the day 2 response level was at the same level as the day 1 response level of trained worms. Thus, if heat shock treatment alone has no direct effect on day 2 performance, we would expect that the day 2 response of the HS ONLY control group would be equal to the day 1 response level of the LTH-HS group (see Fig. 5; note that in the LTH-HS group, the first heat shock treatment comes after block 1 from which the day 1 block response level is calculated). The day 2 response level of the HS ONLY group was at the same level as the day 1 response level of the LTH-HS group [unpaired, two-tailed $t$ test; $t(34)=1.44$, N.S.].

The LTH-HS group from experiment 3 and the LTH group from experiment 2 may be compared directly to confirm that these two groups start at similar levels, and that the difference between the two is in the change in response levels from day 1 to day 2 . The day 1 response levels of the LTH group and the LTH-HS (Figs. 2 and 5, respectively) were not significantly different (unpaired, two-tailed $t$-test; $t(36)=1.031$, N.S.]. This finding indicates that failure to show learning in the LTH-HS group was not attributable to a lower initial response level on day 1 but to a failure to exhibit a decrease in response level between day 1 and day 2.

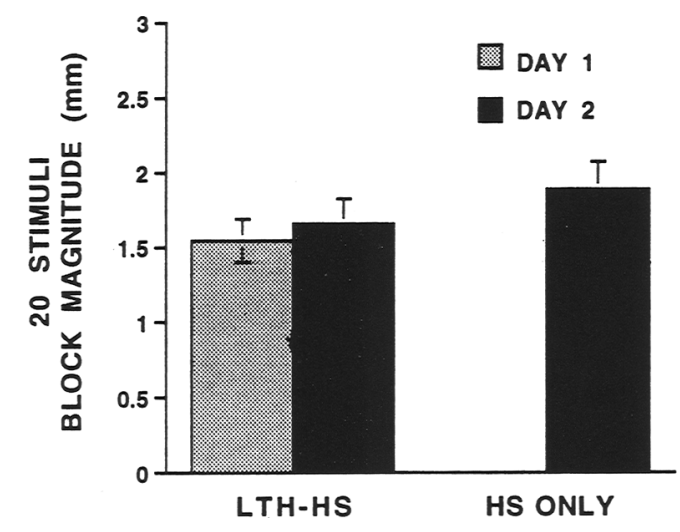

Figure 5: Habituation by block: distributed habituation training with heat shock $\left(45 \mathrm{~min}\right.$ at $\left.32^{\circ} \mathrm{C}\right)$ during training. The mean block magnitudes on day 1 and day 2 of the two groups are shown (LTH-HS) heat shock during distributed training, $n=18$; (HS ONLY) heat shock without training on day $1, n=18$; error bars show $+ \pm /$ - S.E.

\section{Experiment 4}

\author{
SHORT- AND LONG-TERM HABITUATION WITH \\ PRE-EXPOSURE TO HEAT SHOCK AND HEAT \\ SHOCK DURING TRAINING
}

One of the earliest and best-documented phenomena related to the heat shock response is the thermal tolerance effect (Lindquist 1986). When given a severe heat shock, cells in culture died. However, if the cell culture was given a pretreatment of a mild heat shock, then given the severe heat shock, the cells survived. In some systems, the accumulation of HSPs from the early mild heat shock is responsible for the thermal tolerance of the severe heat shock (Lindquist 1986; Parsell et al. 1993). In this context, the accumulation of HSPs from pre-exposure to heat shock may protect the formation of LTM for habituation training from disruption of heat shock during training. In this experiment, the effects of pre-exposure to heat shock on the disruption of LTM formation by heat shock during training were examined.

\section{Materials and Methods}

Three groups were run. The first group, PRE HS/LTH-HS $(n=20)$, received a heat shock ( 45 min at $32^{\circ} \mathrm{C}$ ) that ended $2 \mathrm{hr}$ before the beginning of habituation training on day 1 . During habituation training, heat shock was presented after each of the three training blocks during the $1-\mathrm{hr}$ rest periods. The second group, LTH-HS $(n=20)$, was a replication of the disrupting effects of heat shock during treatment observed in experiment 3 . As in experiment 3 , the LTH-HS group received habituation training with heat shock $\left(45 \mathrm{~min}\right.$ at $32^{\circ} \mathrm{C}$ ) after each of the three training blocks during the 1-hr rest periods. The third group, LTH $(n=19)$, was a control group that received only training. All groups received a test of 20 stimuli on day 2 .

\section{Results}

\section{IMMEDIATE HABITUATION}

The PRE HS/LTH-HS, LTH-HS, and LTH groups (Fig. 6, A, B, and $\mathrm{C}$, respectively) all showed significant habituation over all the training on day 1. There was a significant decrease in response magnitude from the initial stimuli to the final stimuli of training [unpaired, one-

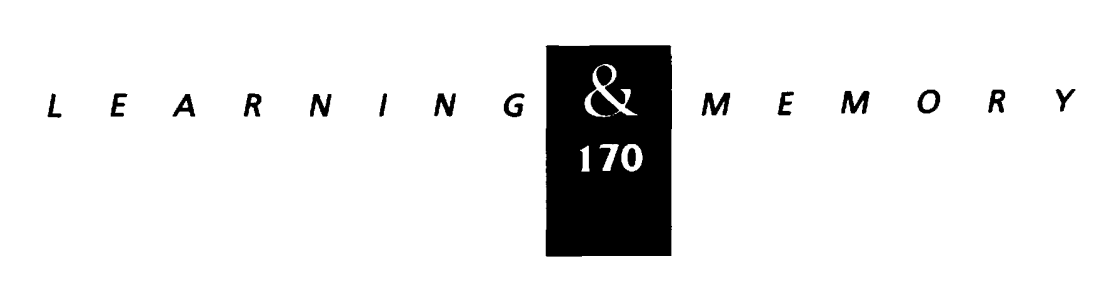


tailed $t$-tests-PRE HS/LTH-HS: $t(30)=3.991$, $P<0.01$; LTH-HS: $t(29)=4.783, P<0.01$; LTH: $t(25)=4.49, P<0.01]$.

Within all blocks of training, the PRE HS/ LTH-HS group showed significant habituation as seen in comparisons of the response magnitude to the initial and final stimuli of the blocks [un- paired, one-tailed $t$ tests-block 1: $t(31)=3.422$, $P=0.01$; block 2 : $t(26)=4.208, P<0.01$; block 3 : $t(30)=3.044, P<0.01]$. In the first and third blocks, the LTH-HS group showed significant habituation as seen in comparisons of the first and last stimuli of the blocks [block 1: $t(27)=4.677$, $P<0.01$; block 3: $t(30)=2.629, P<0.01]$, whereas

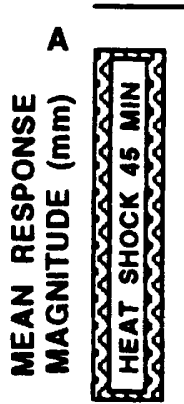

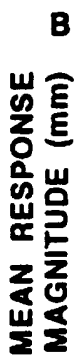

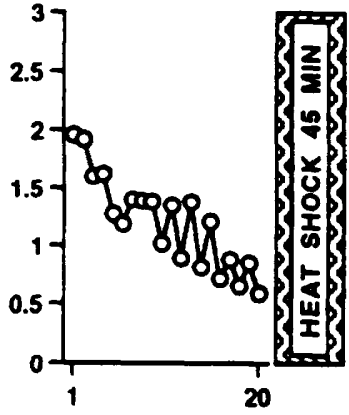

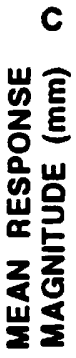

DAY 1
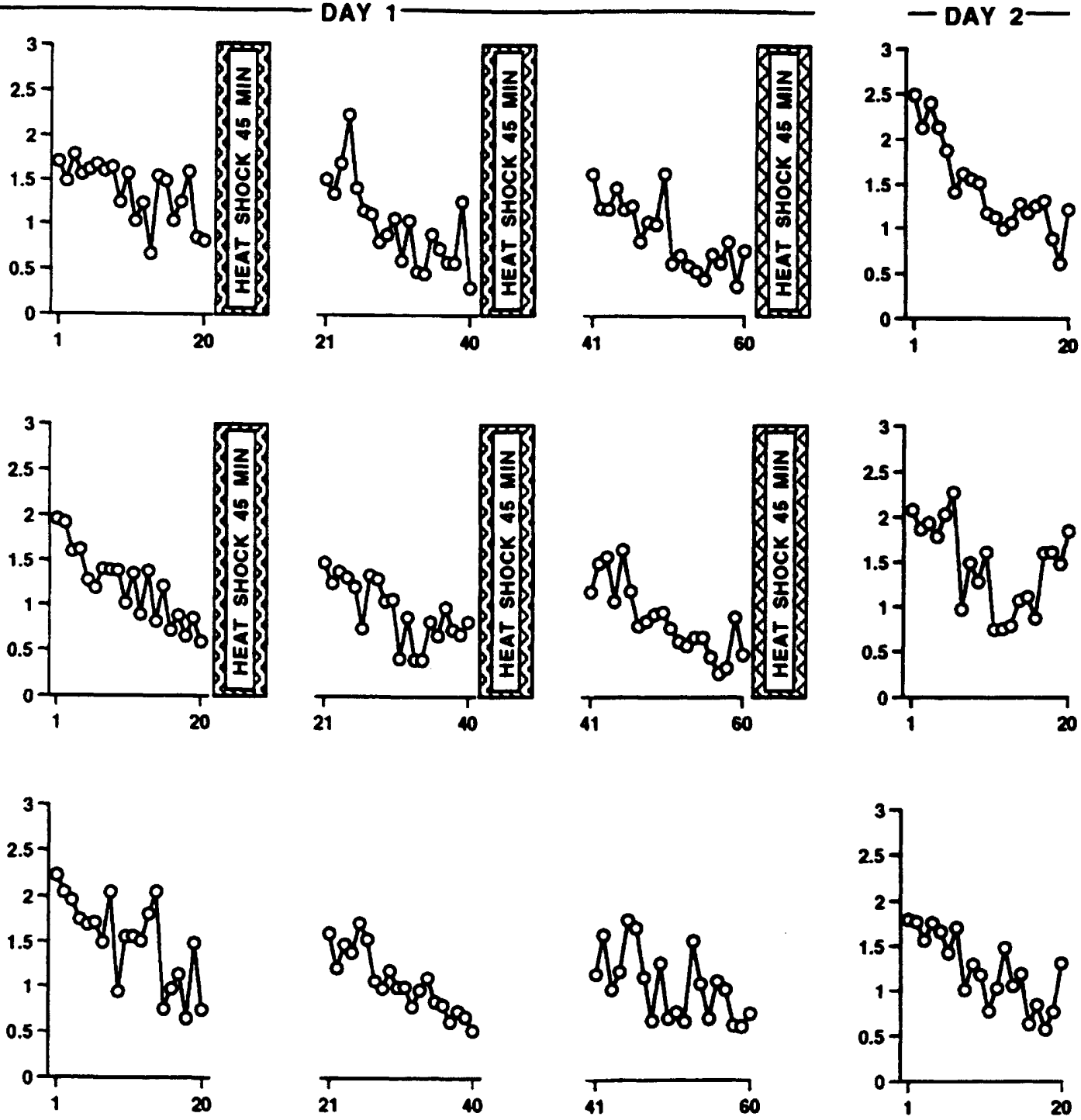

\section{STIMULI}

Figure 6: Habituation curves: distributed habituation training with pre-exposure to heat shock $\left(45\right.$ min at $\left.32^{\circ} \mathrm{C}\right)$ and heat shock during training $\left(45 \mathrm{~min}\right.$ at $32^{\circ} \mathrm{C}$ ). The mean response magnitude $(\mathrm{mm})$ to each stimulus given during training on day 1 and testing on day 2, $24 \mathrm{hr}$ after the end of training, is shown for subjects receiving distributed habituation training (60 stimuli in three blocks of 20 stimuli at a 60 -sec ISI with 1-hr rests between blocks) with pre-exposure to heat shock and heat shock after each of the three training blocks [(A) PRE HS/LTH-HS; $n=20]$, subjects receiving distributed training with heat shock $\left(45 \mathrm{~min}\right.$ at $\left.32^{\circ} \mathrm{C}\right)$ after each of the three training blocks $[(B) \mathrm{LTH}-\mathrm{HS} ; n=20]$, and subjects receiving only training $[(C) \mathrm{LTH} ; n=19]$.

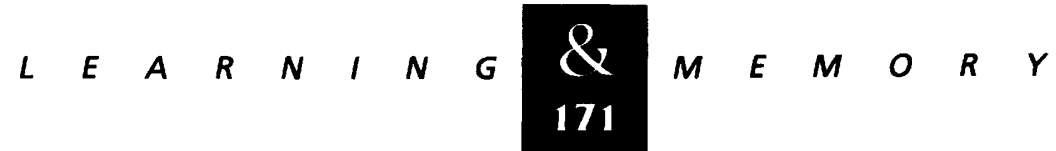


in the second block it did not [block 2: $t(18)=1.716$, N.S.]. In the first and second blocks, the LTH group showed significant habituation as seen in comparisons of the first and last stimuli of the blocks [block 1: $t(24)=3.8, P<0.01$; block 2 : $t(25)=3.312, P<0.01]$, whereas in the third block it did not [block 3: $t(26)=1.533$, N.S.]. The reasons for the failure to see a significant decrease in response magnitude in the second block of the LTH-HS group and the third block of the LTH group are not clear. However, overall, it appears that the expression of habituation within blocks of training is not affected by heat shock before and during training.

Recovery from habituation, as indicated by a significant increase in the response magnitudes from the end of one block to the beginning of the next, was evident in the PRE HS/LTH-HS group between both the first and second blocks and the second and third blocks [unpaired, onetailed $t$ tests-block 1 to block 2: $t(30)=2.266$, $P<0.0154$; block 2 to block 3: $t(27)=4.847$, $P=0.0001$ ] . In the LTH-HS group, recovery from habituation was evident between the first and second blocks but not between the second and third blocks [block 1 to block 2: $t(24)=2.908$, $P=0.0039$; block 2 to block 3: $t(22)=0.882$, N.S.]. In the LTH group, recovery from habituation was evident between the first and second blocks and between the second and third blocks [block 1 to block 2: $t(27)=2.582, P<0.01$; block 2 to block 3 : $t(23)=1.936, P=0.03$ ]. It appears that recovery from habituation is not affected by the combination of heat shock before and during training.

\section{SHORT-TERM RETENTION OF HABITUATION}

Short-term retention of habituation would be exhibited as a significant decrease in the response level across blocks of training. Although the PRE HS/LTH-HS group showed no significant decrease of response magnitudes to the initial stimuli of the blocks of training [factorial ANOVA; $F(2$, $50)=0.336$, N.S.], there was a significant decrease in the block magnitudes across blocks [repeated measures ANOVA; $F(2,38)=5.717, P<0.01]$. In the LTH-HS group, there was both a significant decrease in the response magnitudes to the initial stimuli of the blocks of training [factorial ANOVA; $F(2,43)=3.933, P<0.03$ ], and a significant decrease in the block magnitudes across blocks of training [repeated measures ANOVA; $F(2$,
$38)=10.382, P<0.01]$. In the LTH group, there was a significant decrease in the response magnitudes to the initial stimuli of the blocks of training $[F(2,43)=5.474, P<0.01]$, and a significant decrease in the block response levels across blocks of training $[\mathrm{F}(2,36)=11.12, P<0.01]$. From the results of the analyses of the block response levels, it is clear that all three groups exhibited shortterm retention of habituation training.

\section{LONG-TERM RETENTION OF HABITUATION TRAINING}

Retention of habituation training would be evident as a lower level of response on day 2 than on day 1. In both the PRE HS/LTH-HS and the LTH-HS groups, the response levels did not change between day 1 and day 2 , indicating that LTM for habituation training was blocked in both groups [see Fig. 7; paired, two-tailed $t$-testsPRE HS/LTH-HS: $t(19)=1.058$, N.S.; LTH-HS: $t(19)=1.736$, N.S.]. However, in the LTH group, the response level decreased significantly from day 1 to day 2 , indicating that long-term habituation was retained [LTH: $t(18)=1.797, P=0.04$ ]

THE EFFECTS OF PRE-EXPOSURE TO HEAT SHOCK ON THE DISRUPTION OF LTM BY HEAT SHOCK DURING TRAINING

Based on the results of experiments 2 and 3, where it was observed that pre-exposure to heat

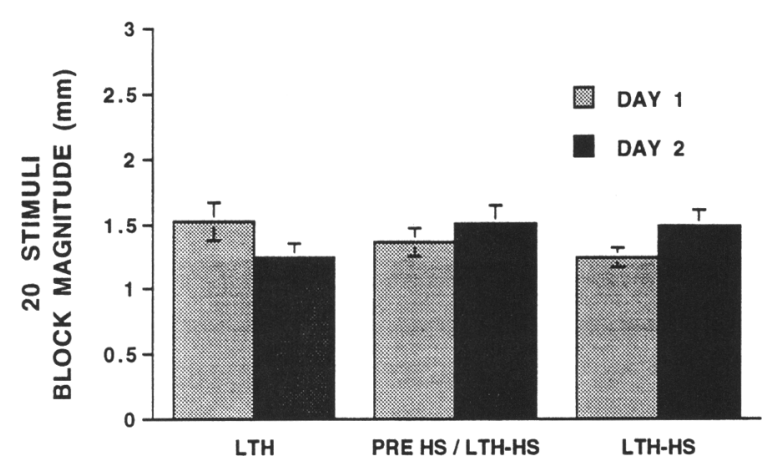

Figure 7: Habituation by block: distributed habituation training with pre-exposure to heat shock (45 $\mathrm{min}$ at $32^{\circ} \mathrm{C}$ ) and heat shock during training $\left(45 \mathrm{~min}\right.$ at $32^{\circ} \mathrm{C}$ ). The mean block magnitudes on day 1 and day 2 of the three groups that received training on day 1 . [the PRE HS/LTH-HS), heat shock distributed before and during training, $n=20$; l(LTH-HS) heat shock distributed during training only, $n=20$; and (LTH) heat shock distributed during training only, $n=9$; error bars shown \pm s.E.].

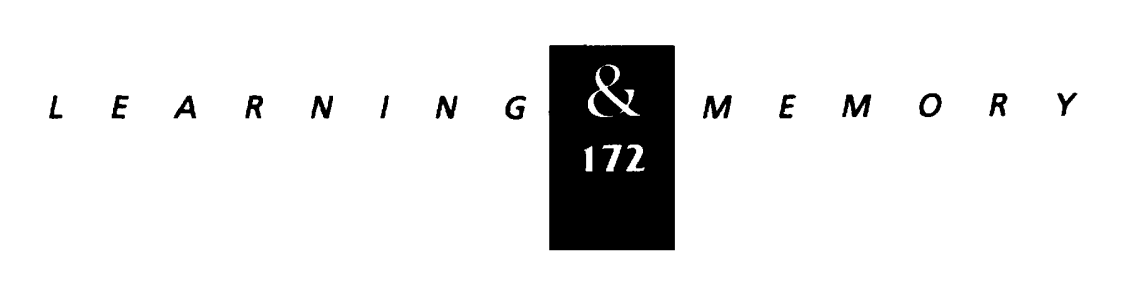


shock did not affect short- or long-term habituation while heat shock during training disrupted the formation of LTM for habituation training, it seems likely that the disruption of LTM seen in these results is also attributable to the heat shock that both groups received during training. When the day 1 response levels of the groups are compared, there is no significant difference [factorial ANOVA: $F(2,56)=1.577$, N.S.]. To determine whether the pretraining heat shock produced differences in the amount of LTM for habituation training a difference score was calculated for each animal by subtracting its day 2 block mean score from its day 1 block 1 mean score. When these difference scores are compared across the groups, there were no differences between the groups that received heat shock, however, the difference scores of the LTH group are significantly larger than the difference scores of the two groups that received heat shock during training [factorial ANOVA: $F(2,56)=3.696, P=0.03$ ]. Because both of the LTH-HS groups differ from the LTH group in their expression of long-term habituation and do not differ from each other we can conclude that pre-exposure to heat shock did not prevent the block of LTM formation by heat shock during training.

\section{Experiment 5}

THE EFFECTS OF HEAT SHOCK JUST PRIOR TO TESTING ON THE RETENTION OF LONG-TERM HABITUATION

In experiment 2, pre-exposure to heat shock did not prevent the formation of LTM, in experiment 3 , heat shock during training blocked the formation of LTM. In this experiment, the effect of heat shock on the retention of memory is tested. Heat shock before the day 2 retention test long after training may affect the processes necessary for the retention of long-term habituation.

\section{Materials and Methods}

Three groups were run. The first group, LTH $(n=19)$, received only training. The second group, LTH/DAY 2 HS $(\boldsymbol{n}=20)$, received training and received a heat shock ending $2 \mathrm{hr}$ before testing on day 2. The third group, DAY 2 HS ONLY $(n=20)$, received only a single stimulus on day 1 but, like the LTH/DAY 2 HS group, received a heat shock ending $2 \mathrm{hr}$ before testing on day 2 . Only the long-term retention of habituation will be analyzed in the results as the heat shock was presented after training on day 1 was complete.

\section{Results}

\section{LONG-TERM RETENTION OF HABITUATION}

Retention of habituation training would be evident as a lower level of response on day 2 than on day 1. In the LTH and LTH/DAY 2 HS groups, the response levels on day 2 was significantly lower than those on day 1 , indicating that day 2 heat shock did not block the decrease in response level with training [see Fig. 8; paired, one-tailed $t$-testsLTH: $t(18)=2.159, P=0.02$; LTH/DAY 2 HS: $t(19)=3.792, P<0.01]$

\section{THE EFFECTS OF DAY 2 HEAT SHOCK}

It is possible that the day 2 heat shock given in the LTH/DAY 2 HS group had a direct effect on the level of responding during testing. If the day 2 heat shock had no effect, the response level on day 1 of the LTH and the LTH/DAY 2 HS groups should be at the same as the response level on day 2 of the

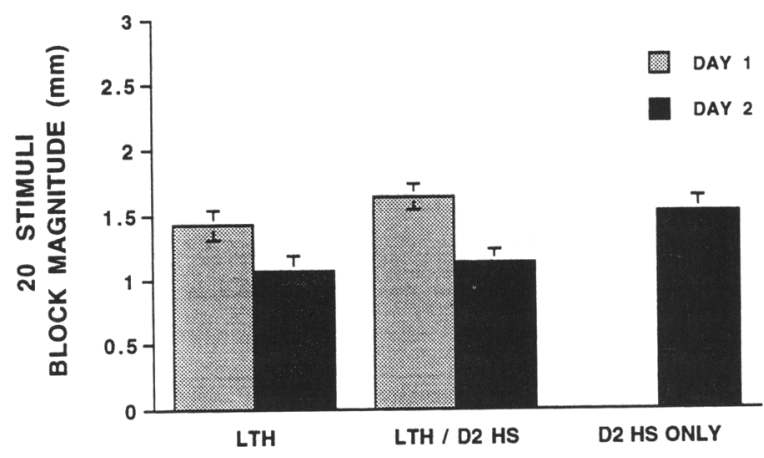

Figure 8: Habituation by block: distributed habituation training with heat shock $\left(45 \mathrm{~min}\right.$ at $\left.32^{\circ} \mathrm{C}\right)$ on day 2 , $2 \mathrm{hr}$ before testing. The mean block magnitudes on day 1 and day 2 of the group that received only training, [LTH $(n=19)$ ]; the group that received training on day 1 and heat shock before the retention test on day 2 [LTH/ D2 HS $(n=20)]$; and the DAY 2 HS ONLY $(n=20)$ group are shown (error bars show \pm S.E.). The DAY 2 HS ONLY group received only a single stimulus on day 1 , no habituation training, and a heat shock on day 2 that ended $2 \mathrm{hr}$ before the retention test.

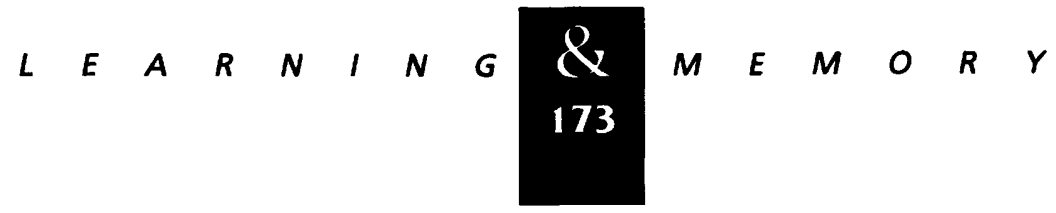


DAY 2 HS ONLY group. As can be seen in Figure 8, there was no significant difference between the level of response initially on day 1 of the LTH and LTH/DAY 2 HS groups and the level of response on day 2 of the DAY 2 HS ONLY group [factorial ANOVA: $F(2,56)=0.934$, N.S.]. In addition, if the day 2 heat shock did not affect long-term habituation, the response level on day 2 of the LTH group should be the same as the response level on day 2 of the LTH/DAY 2 HS group, and less than the day 2 response level of the DAY 2 HS ONLY group. This was the case [factorial ANOVA: $\boldsymbol{F ( 2 ,}$ $56)=4.867, P=0.01]$. Thus, the day 2 heat shock had no direct effect on the level of response on day 2 , and furthermore, did not disrupt the retention of LTM for habituation.

\section{Experiment 6}

\section{TITRATION OF THE EFFECTS OF HEAT SHOCK DURING THE REST PERIOD}

Work with Aplysia and other systems has emphasized the dynamics of the cellular processes that support LTM (Byrne et al. 1993). In experiments 3 and 4, we have seen that in $C$. elegans, heat shock delivered during the rest periods of distributed training disrupts the retention of LTM for habituation training. Unlike the protein synthesis inhibitors used in work with Aplysia, heat shock can be delivered in brief, discrete pulses. Thus, it may be possible to titrate the timing of heat shock to begin to explore whether there is a shorter interval within the 1 -hr rest period during which LTM formation is particularly vulnerable to disruption. In this experiment, the effects of brief heat shock $\left(15 \mathrm{~min}, 32^{\circ} \mathrm{C}\right)$ given either early, midway or late in the 1 -hr rest periods on the retention of habituation training were examined.

\section{Materials and Methods}

Four groups were run. All groups received habituation training on day 1 and were tested on day 2 . The first group, LTH $(n=20)$, received no heat shock in the 1 -hr rest periods during training. The second group, LTH-EARLY HS $(n=20)$, received 15-min heat shock from $0-15 \mathrm{~min}$ in the 1 -hr rest periods during training. The third group, LTH-MID HS $(n=20)$, received 15-min heat shock from 15$30 \mathrm{~min}$ in the $1-\mathrm{hr}$ rest periods during training.
The fourth group, LTH-LATE HS $(n=20)$, received 15 -min heat shock from $30-45 \mathrm{~min}$ in the 1-hr rest periods during training. Only long-term habituation was considered in the analysis because the longer duration 45-min heat shock used in experiments 2, 3-4 did not affect the expression of habituation during training on day 1 nor the shortterm retention of habituation.

\section{Results}

\section{LONG-TERM RETENTION OF HABITUATION TRAINING}

Retention of habituation training would be evident as a lower level of response on day 2 than on day 1. As can be seen in Figure 9, in the LTH, LTH-EARLY HS, and LTH-LATE HS groups, the response levels on day 2 were significantly lower than on day 1 , indicating that habituation training alone or with either early or late 15-min heat shock produced LTM for habituation [paired, onetailed $t$-tests-LTH: $t(19)=3.073, P<0.01$; LTHEARLY HS: $t(19)=2.845, P<0.01$; LTH-LATE HS: $t(19)=4.059, P<0.01]$. However, in the LTH-MID HS group, there was no difference between the response levels on day 1 and day 2 [LTH-MID HS:

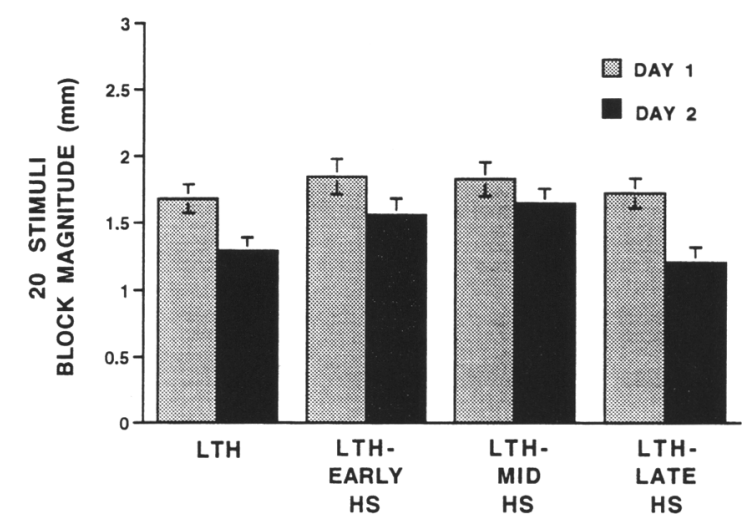

Figure 9: Habituation by block: distributed habituation training alone or with brief heat shock (15 min at $32^{\circ} \mathrm{C}$ ) during training either early, midway or late in the 1 -hr rest period following each training block. The mean block magnitudes on day 1 and day 2 of all four of the groups: (the LTH group) $n=20$; no heat shock during 1 -hr rest periods; (the LTH-EARLY HS group) $n=20$; heat shock from 0-15 min in the 1-hr rest periods; (the LTH-MID HS group) ( $n=20$ : heat shock from 15 to 30 $\mathrm{min}$ in the 1 -hr rest periods; and (the LTH-LATE HS group) $n=20$; heat shock from 30 to $45 \mathrm{~min}$ in the 1-hr rest periods; (error bars show \pm S.E.).

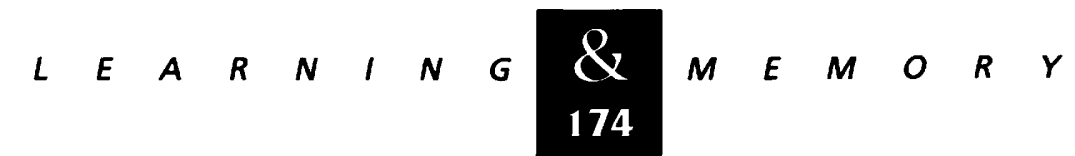


$t(19)=1.283$, N.S.]. These findings suggest that heat shocks given at different times in the 1-hr interval following training blocks have different effects on LTM formation.

\section{THE EFFECTS OF 15-MIN HEAT SHOCK ON LTM}

To explore the possibility that the heat shocks given at different times have different effects on LTM, analyses were performed comparing only the groups that received heat shock. A comparison of day 1 response levels across the LTH-EARLY HS, LTH-MID HS, and LTH-LATE HS groups showed that there were no significant differences between the groups $[F(2,57)=0.274$, N.S.]. To test for effects on LTM day 2-day 1 difference scores were compared across the groups. There was a significant difference in the difference scores between the groups that received heat shock at different times $[F(2,57)=12.229, P<0.01]$. Post hoc comparisons indicated that the disruption in LTM for habituation training was significantly greater for groups that received heat shock early and midway through the intervals when compared with the group that received heat shock late in the interval. This finding suggests that brief heat shocks given at different times in the intervals following training blocks may have different effects on LTM formation, and that the first half-hour following training may be particularly vulnerable to the effects of heat shock.

\section{Discussion}

In these experiments, the role of the rest period during distributed training in memory formation was examined. In this approach, heat shock treatments were introduced before, during and long after distributed habituation training. These treatments may perturb the cellular processes that are necessary for memory formation without interrupting spontaneous recovery from habituation. It was found that heat shock presented before or long after training did not affect LTM for habituation; however, heat shock given during training did disrupt LTM for habituation. Although a single heat shock did cause the induction of bsp16, a heat shock gene, heat shock before training did not induce thermal tolerance for the effects of heat shock during training on LTM for habituation. Finally, there was preliminary evidence that ITM may be particularly vulnerable to disruption by brief heat shock given early or midway through the 1-hr interval following training blocks as opposed to late in those intervals. This last finding suggests that the critical period for memory consolidation of habituation training may be quite brief and specific; however, more studies are needed to confirm and expand on this possibility.

One problem that has interfered with the interpretation of the results from studies examining the blocking of memory formation is that many agents that affect cellular processes make the organism sick; the change in the behavior observed with the treatment with the agent may be a result of the sickness, not a specific failure to form LTM (see Davis and Squire 1984 for a discussion of how such effects can be dissociated in work with protein synthesis inhibitors). In work with Aplysia, this problem is partly dealt with by using reduced preparations or cell culture. However, with these approaches, behavioral information from the whole organism is not accessible. One advantage of using habituation as a learning paradigm in this context is that the successful block of LTM for habituation by an agent results in a higher day 2 level of response relative to trained, untreated controls, whereas sickness from the treatment should result in a lower day 2 level of response. Thus, in a habituation paradigm it is less likely that the side-effects of the treatment will confound the failure to remember the training.

As a tool to investigate the dynamics of memory consolidation, heat shock has some critical advantages. First, it can be administered easily, without disturbing the organism or introducing any exogenous substances. Second, unlike cold shock and other anesthetics, it does not cause paralysis. C. elegans continues to move and forage during moderate heat shock and is able to respond to tactile stimuli normally immediately after treatment. Third, unlike chemical agents that affect protein synthesis, heat shock can be administered for a defined, brief period of time. Fourth, heat shock evokes an active cellular response, which is interesting in and of itself; but more importantly, the interaction of the cellular response to heat shock and the plasticity expressed in the tap withdrawal reflex may be a model system for the examination of interactions between organism-wide responses to changes in the environment and plasticity specifically by the nervous system.

It is not possible with the present information to determine how heat shock has its effects on

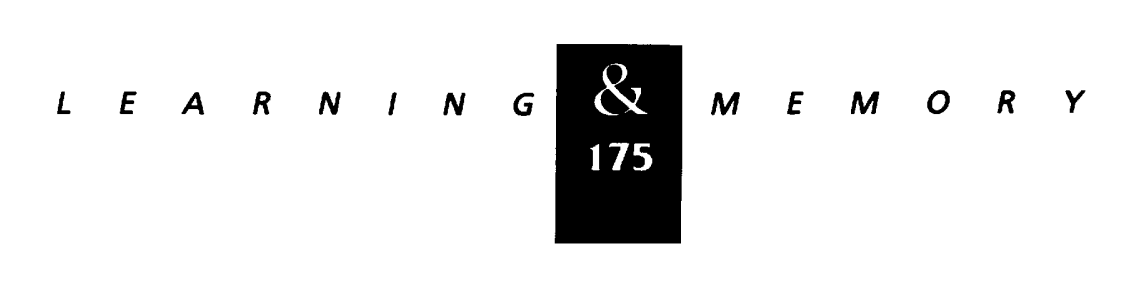


LTM. The simple presence of HSPs is unlikely to be disruptive to LTM formation, as the pretreatment with heat shock ( $2 \mathrm{hr}$ before training) did not affect LTM for habituation. However, the body of work on HSPs in other systems has indicated that heat shock evokes the expression of a number of HSPs, varying in their duration and type of action; furthermore, there are great differences between species and between tissue types within a species in the expression of HSPs (Schlesinger et al. 1982; Lindquist 1986; Nowak 1993). Little as yet is known about HSP expression specifically in the nervous system of $C$. elegans; more information on the nature and function of the heat shock response in $C$. elegans would be helpful to this investigation.

A possible critical factor in the effect of the heat shock response on LTM is the protein synthesis inhibition caused by heat shock. It has been demonstrated in a number of systems that protein synthesis inhibitors block LTM formation (Davis and Squire 1984; Tully et al. 1995). In future experiments the importance of this factor to LTM disruption in $C$. elegans will be investigated directly using protein synthesis inhibitors in conjunction with training.

In summary, short-term habituation within training blocks and short-term retention of habituation between training blocks on day 1 were unaffected by heat shock given during training, whereas long-term habituation was blocked by heat shock during training. These findings suggest that the cellular processes underlying short-term habituation and short-term accumulation of habituation are resistant to disruption by heat shock, but that the cellular processes supporting LTM formation are vulnerable to such disruption. Heat shock before or long after training did not affect the expression of LTM. The possibility of a narrow critical period within the 1 -hr interval following training blocks is definitely worth investigation. In conclusion, the addition of heat shock to the techniques available in the study of the cellular bases of learning and memory gives us a fine-grained tool for the exploration of the temporal parameters of memory consolidation.

\section{Acknowledgments}

These experiments were run by C.D.O.B. in partial fulfillment of the requirements of a doctoral degree at the University of British Columbia (UBC). C.D.O.B. was supported by a National Sciences and Engineering Research
Council (NSERC) PGS, and C.H.R. was supported by operating grants from NSERC and from the Human Frontiers of Science Program. We acknowledge the help of Tracey Smillie, Richard Faber, Michael McCready, Frank Lai, and Terry Zulynk in running worms and/or scoring data, as well as editorial feedback from Stephen Wicks, Eric Eich, and Anthony Phillips. We also acknowledge Dr. Peter Candido of the Department of Biochemistry at UBC for heat shock expertise and use of the $h s p / / / a c Z$ strain.

The publication costs of this article were defrayed in part by payment of page charges. This article must therefore be hereby marked "advertisement" in accordance with 18 USC section 1734 solely to indicate this fact.

\section{References}

Bailey, C.H. and M. Chen. 1983. Morphological basis of long-term habituation and sensitization in Aplysia. Science 220: 91-93.

1988a. Long-term memory in Aplysia modulates the total number of varicosities of single identified sensory neurons. Proc. Natl. Acad. Sci. 85: 9356-9359.

1988b. Long-term sensitization in Aplysia increases the number of presynaptic contacts onto the identified gill motor neuron L7. Proc. Natl. Acad. Sci. 85: 9356-9359.

Bargmann, C.I. 1993. Genetic and cellular analysis of behavior in C. elegans. Annu. Rev. Neurosci. 16: 47-71.

Beck, C.D.O. 1995. "Factors affecting long-term habituation in Caenorhabditis elegans." Ph.D. dissertation, University of British Columbia, Vancouver.

Brenner, S. 1974. The genetics of the nematode Caenorhabditis elegans. Cenetics 77: 71-94.

Byrne, J.H., R. Zwartjes, R. Homayouni, S.D. Critz, and A. Eskin. 1993. Roles of second messenger pathways in neuronal plasticity and in learning and memory. In Advances in Second Messenger and Phosphoprotein Research (ed. S. Shendlikar and A.C. Nairn), Vol. 27, pp. 47-108. Raven Press, New York.

Carew, T.J. and E.R. Kandel. 1973. Acquisition and retention of long-term habituation in Aplysia: Correlation of behavioral and cellular processes. Science 182: 1158-1160.

Carew, T.J., H.M. Pinsker, and E.R. Kandel. 1972. Long-term habituation of a defensive withdrawal reflex in Aplysia. Science 175: 451-454.

Castellucci, V.F., H. Blumenfeld, P. Goelet, and E.R. Kandel. 1989. Inhibitor of protein synthesis blocks long-term behavioral sensitization in the isolated gill-withdrawal reflex of Aplysia. J. Neurobiol. 20: 1-9.

Dalley, B.K. and M. Golomb. 1992. Gene expression in the Caenorhabditis elegans dauer larva: Developmental regulation of $h s p 90$ and other genes. Dev. Biol. 151: 80-90.

Davis, H.P. and L.R. Squire. 1984. Protein synthesis and memory: A review. Psychol. Rev. 96: 518-559.

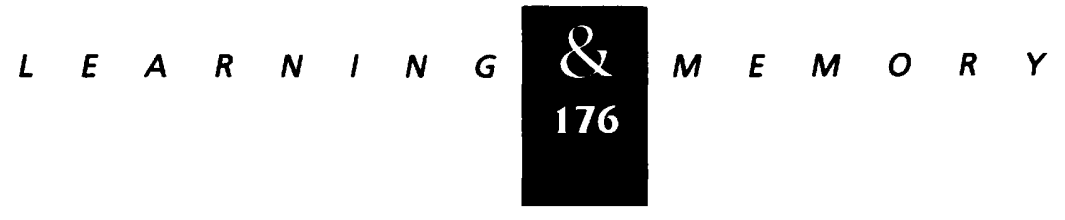


Fire, A., S. White-Harrison, and D. Dixon. 1990. A modular set of $\boldsymbol{\beta}$-galactosidase fusion vectors for studying gene expression in Caenorhabditis elegans. Gene 93: 189-198.

Flood, J.F., E.L. Bennett, A.E. Orme, and M.E. Jarvik. 1977. Protein synthesis gradient of ECS retrograde amnesia. Behav. Biol. 21: 307-328.

Frey, U., M. Krug, K.G. Reymann, and H. Matthies. 1988. Anisomycin, an inhibitor of protein synthesis, blocks late phases of LTP phenomena in the hippocampal CA1 region in vitro. Brain Res. 452: 57-65.

Ghirardi, M., P.G. Montarolo, and E.R. Kandel. 1995. A novel intermediate stage in the transition between short- and long-term facilitation in the sensory to motor neuron synapse of Aplysia. Neuron 14: 413-420.

Groves, P.M. and R.F. Thompson. 1970. Habituation: A dual-process theory. Psychol. Rev. 77: 419-450.

Hall, D.H. and R.L. Russell. 1991. The posterior nervous system of the nematode Caenorhabditis elegans: Serial reconstruction of identified neurons and complete pattern of synaptic interactions. J. Neurosci. 11: 1-22.

Heschl, M.F.P. and D.L. Baillie. 1990. The HSP70 family of Caenorhabditis elegans. Comp. Biochem. Physiol.

96B: 633-637.

Koroshetz, W.J. and J.V. Bonventre. 1994. Heat shock response in the central nervous system. Experientia 50: 1085-1091.

Lindquist, S. 1986. The heat-shock response. Annu. Rev. Biochem. 55: 1151-1191.

Mizumori, S.J.Y., M.R. Rosenzweig, and E.L. Bennett. 1985. Long-term working memory in the rat: effects of hippocampally applied anisomycin. Behav. Neurosci. 99: 220-232.

Montarolo, P.G., P. Goelet, V.F. Castellucci, J. Morgan, E.R. Kandel, and S. Schacher. 1986. A critical period for macromolecular synthesis in long-term heterosynaptic facilitation in Aplysia. Science 234: 1249-1254.

Montarolo, P.G., E.R. Kandel, and S. Schacher. 1987. Long-term heterosynaptic depression of the sensorimotor synapses in culture is produced by the peptide FMRF-amide. Soc. Neurosci. Abstr. 13: 391.

Nowak, T.S. 1993. Synthesis of heat shock/stress proteins during cellular injury. Ann. N.Y. Acad. Sci. 679: 142-156.

Parsell, D.A., J. Taulien, and S. Lindquist. 1993. The role of heat shock proteins in thermotolerance. Phil. Trans. R. Soc. Lond. B 339: 279-286.

Rankin, C.H., C.D.O. Beck, and C.M. Chiba. 1990. Caenorhabditis elegans: A new model system for the study of learning and memory. Behav. Brain Res. 37: 89-92.
Russnak, R.H. and P.M. Candido. 1985. Locus encoding a family of small heat shock genes in Caenorhabditis elegans: Two genes duplicated to form a 3.8-kilobase inverted repeat. Mol. Cell. Biol. 5(6): 1268-1278.

Schacher, S., P.G. Montarolo, E.R. Kandel, M. Chen, and C.H. Bailey. 1991. Inhibitors of protein and RNA synthesis block structural changes accompanying long-term presynaptic facilitation and inhibition in Aplysia sensory neurons. Soc. Neurosci. Abstr. 17: 1301.

Schlesinger, M.J., A. Tissieres, and M. Ashburner. 1982. Heat shock proteins: From bacteria to man. Cold Spring Harbor Laboratory, Cold Spring Harbor, New York.

Sharp, F.R. and S.M. Sagar. 1994. Alterations in gene expression as an index of neuronal injury: heat shock and the immediate early gene response. NeuroToxicity 15: 51-60.

Snutch, T.P. and D.L. Baillie. 1983. Alterations in the pattern of gene expression following heat shock in the nematode Caenorhabditis elegans. Can. J. Cell Biol. 61: 480-487.

Stringham, E.P., D.K. Dixon, D. Jones, and E.P. Candido. 1992. Temporal and spatial expression patterns of the small heat shock (Hsp 16) genes in transgenic Caenorhabditis elegans. Mol. Biol. Cell 3: 221-233.

Tully, T., T. Preat, S.C. Boynton, and M. Del Vecchio. 1994. Genetic dissection of consolidated memory in Drosophila. Cell 79: 35-47.

White, J.G., E. Southgate, J.N. Thomson, and S. Brenner. 1986. The structure of the nervous system of Caenorhabditis elegans. Phil. Trans. R. Soc. Lond. B. 314: 1-340.

Wood, W.B., ed. 1988. The nematode Caenorhabditis elegans. Cold Spring Harbor Laboratory, Cold Spring Harbor, New York.

Received May 12, 1995; accepted in revised form August 15, 1995.

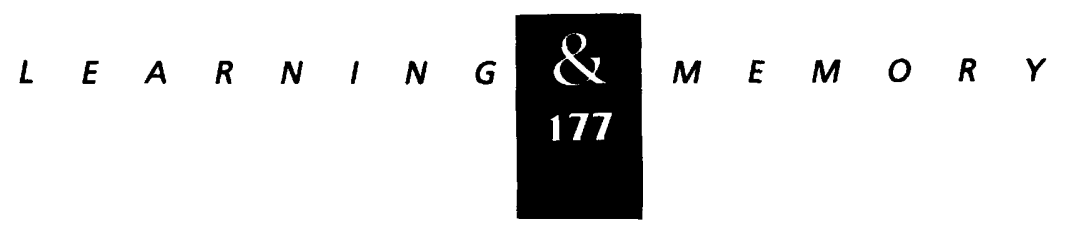




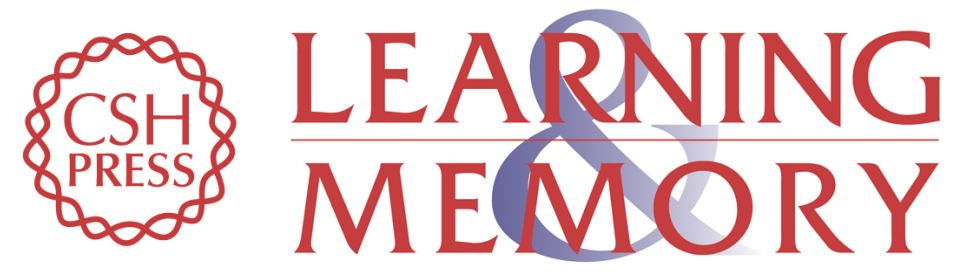

\section{Heat shock disrupts long-term memory consolidation in Caenorhabditis elegans.}

C D Beck and C H Rankin

Learn. Mem. 1995, 2:

References This article cites 32 articles, 9 of which can be accessed free at: http://learnmem.cshlp.org/content/2/3-4/161.full.html\#ref-list-1

License

Email Alerting

Receive free email alerts when new articles cite this article - sign up in the box at the Service top right corner of the article or click here. 